\title{
Aviator performance in week-long extended flight operations in a helicopter simulator
}

\author{
GERALD P. KRUEGER, RICHARD N. ARMSTRONG, and RONALD R. CISCO \\ U.S. Army Aeromedical Research Laboratory, Fort Rucker, Alabama
}

\begin{abstract}
Psychological, physiological, and biochemical correlates of aviator crew performance, stress, and fatigue were measured in a week-long flight schedule in a helicopter simulator. Three twoman crews of rotary wing aviators performed $14 \mathrm{~h}$ of precision instrument flight on each of 4 successive days and $10 \mathrm{~h}$ on the 5 th day. Missions involved repetitions of 2-h standardized day and night flight profiles that were occasionally interrupted by simulated emergencies. Aviator performance measures included meeting assigned airspeeds, altitudes, headings, turn rates, and navigation requirements. Pilots slept $4 \mathrm{~h}$ each night. Baseline data were collected prior to, and recovery data after, the extended flight schedule. Pilots maintained simulator flight parameters to within acceptable tolerances of assigned headings, airspeeds, and altitudes, even into the morning of the 4th day of the schedule. However, cognitive and judgmental errors were made. Even though flight surgeons deemed them unsafe to fly by the 3rd night, pilots continued to fly well to the 5th day.
\end{abstract}

Modern battlefield tactics and technological devices give military forces the capability of conducting warfare for sustained periods, of days, or perhaps even weeks. This capability to wage continuous warfare poses serious aeromedical problems of aviator fatigue when pilots participate in sustained operations or extended flight schedules (Fisher \& Carr, 1968; Krueger \& Fagg, 1981; Krueger \& Jones, 1978; Perry, 1974). Numerous aviator stressors, combined with long flying hours and excessively long work days, bring about the inevitable consequences of fatigue that result in poor performance, unsafe flight, loss of lives, and reduced mission effectiveness.

Kimball and Anderson (1975) demonstrated that newly graduated rotary wing aviators can fly helicopters about $12 \mathrm{~h}$ in each 24-h period for 5 consecutive days with $3.5 \mathrm{~h}$ of sleep per 24-h period. The data reported from that study (Behar, Kimball, \& Anderson, 1976; Kimball \& Anderson, 1975; Lees, Kimball, \& Stone, 1977; Lees, Simmons, Stone, \& Kimball, 1978; Lees, Stone, Jones, Kimball, \& Anderson, 1979) indicate that a pilot's ability to control a helicopter did not degrade as quickly as might have been expected. However, pilot response to the judg-

The authors gratefully acknowledge the six Army aviators who served as subject pilots, the contributions of Major Lawrence R. Whitehurst, M.D., who served as the medical monitor and collected the flight surgeon evaluation data, Dr. Heber D. Jones, who guided and assisted in the 20-h/day week-long data-collection sessions on the USAARL computer, William R. Holt, who guided us in the preparation and analysis of much of the data, and the more than 20 other laboratory research and support personnel who worked with us as associate investigators to make the conduct of this multidisciplinary project possible. Gerald P. Krueger is now with the Division of Neuropsychiatry, Walter Reed Army Institute of Research, Washington, DC. Richard N. Armstrong is now with the U.S. Army Human Engineering Laboratory Detachment at the Aviation Center and School, Fort Rucker, AL. The mailing address of the U.S. Army Aeromedical Research Laboratory is: Fort Rucker, AL 36362-5000. mental and cognitive aspects of flight seemed to deteriorate noticeably after only a few days.

The focus in the Kimball and Anderson study (1975) was on individual pilots, not crews. One pilot at a time was measured in the extended flight schedule. For safety reasons, several rested pilots rotated through the second seat in the cockpit. The pilots were tested on frequent repetitions of 32 different flight maneuvers and tasks.

This experiment was designed to study the performance of pilots, as integral members of pilot-copilot crews, flying complete day and night instrument flight mission scenarios in a helicopter simulator during extensive weeklong operations.

\section{METHODS AND PROCEDURES}

\section{Overview}

Three two-man crews of helicopter aviators underwent 4 pretest days of training and baseline data collection before participating in an extended flight schedule of $66 \mathrm{~h}$ of simulator flight in a 5-day period.

When not flying, aviators participated in laboratory tests of pursuit rotary tracking, visual search tasks, and regular examinations by flight surgeons. These subjects slept approximately $4 \mathrm{~h}$ each night during the test phase. After 2 days of rest, recovery data were collected on a posttest day of flying.

Flight performance, psychological, physiological, oculomotor, and biochemical measures, and subjective ratings of fatigue and performance were collected during the study. We also investigated flight surgeon decisionmaking in the diagnosis of aviator fatigue.

\section{Subjects}

Subjects were six U.S. Army rotary wing aviators rang- 
ing in age from 21 to 28 years. They were all volunteers, recruited from recent graduating flight classes of the U.S. Army's Initial Entry Rotary Wing (IERW) flight program at Fort Rucker, Alabama, where they had logged about 200 flight and simulator hours. Subjects were selected both on the basis of their willingness to participate and on a proper fit of a facial mask for the oculomotor tracking portions of the experiment.

Two physicians served as subjects for the evaluation of flight surgeon decision-making in the diagnosis of aviator fatigue. Neither had had previous field experience as a flight surgeon. Both knew the flight schedules, but not the details, of the study, and they had no access to the data being collected.

\section{Research Facilities}

Facilities included a pilot debriefing room, a physician's examining room, and subject living accommodations.

The simulator was a replica of the U.S. Army's UH1H utility helicopter cockpit with a two-degree-of-freedom motion system. The front windscreen was translucent, allowing for simulation of instrument flight conditions only. The flight controls, instruments, navigation aids, power management gauges, and cockpit switches were the same as those in a standard helicopter. Flight dynamics were controlled by a closed-loop analog computer and were patterned after the aerodynamics of the UH-1H. The motion system provided kinesthetic sensations, but these were not as pronounced as those of real flight. The simulator platform was more stable than the actual helicopter, giving less yaw sensation than the aircraft. Consequently, the pilot had to be more attentive to the simulator turn and slip indicator, pedal controls, and their associated instrument flight parameters during flight.

An on-line, real-time data-acquisition and control system was interfaced with a Systems Engineering Laboratory 8500 digital computer. Measures of 31 flight and pilot status parameters (Table 1) included pilot control movements, geographical position, flight instrument indications, flight dynamics, and cardiovascular signals. Each parameter was sampled 20 times per second. The system continuously collected pilot flight performance data during the $14 \mathrm{~h}$ of flight each day.

\section{Flight Profiles}

All simulator flights were Instrument Flight Rules (IFR) missions and included instrument takeoffs, cross-country flight following navigational aids or air traffic controller instructions, instrument approaches, and landings. Missions included both 1- and 2-h standardized day and night flight missions, which occasionally were interrupted by simulated engine failure emergency situations. A 1-h profile used in the study is depicted in Figure 1. The 2-h flights were approximations of what might be accomplished with one UH-1H fuel load.

\section{Flight Procedures}

Experimenters, serving as air traffic controllers, used standard radio procedures for conversing with the pilots. Intracrew communications and communications between crew and air traffic controllers were recorded. Aviators alternated as pilot at the flight controls or copilot on every other flight, thus allowing for long periods of flight performance measurement for both subjects. The cockpit was darkened to simulate night flight operations the last two flights of the day.

\section{Cardiovascular Monitoring}

Three electrocardiogram chest electrodes were wired to a cardiovascular monitoring system, and data were collected via the simulator data-acquisition system during most flights to assess pilot heart rate and heart rate variability as indicators of alertness and attentiveness.

\section{Short-Term Memory}

Twice during each 2 -h flight, the copilot participated in a simulated navigational task to assess his auditory attention and short-term memory as the extended flight schedule progressed through the week.

The air traffic controller read to the copilot groups of 6,8 , and 10 randomly selected alphanumeric character strings that were similar to sets of military map grid coor-

Table 1

Recorded Flight Parameters

1. Altitude
2. Rate of Climb
3. Heading
4. Pitch Rate
5. Roll Rate
6. Airspeed
7. Cyclic Movement Left/Right
8. Cyclic Movement Fore/Aft
9. Collective Movement
10. Pedal Movement
11. Aircraft Trim
12. Rate of Turn
13. Pitch Attitude
14. Roll Attitude
15. Engine Torque

16. Throttle Position

17. Gas Producer RPM

18. Rotor RPM

19. Longitudinal Velocity

20. Lateral Velocity

21. Ground Position North/South

22. Ground Position East/West

23. Engine Oil Temperature Gauge

24. Caution Warning Light Onset

25. RPM Warning Light Onset

26. Radio Magnetic Indicator, \#1 Needle

27. Radio Magnetic Indicator, \#2 Needle

28. Course Director Indicator, Vertical Needle

29. Course Director Indicator, Horizontal Needle

30. Pilot's Heart Period

31. Copilot's Heart Period 


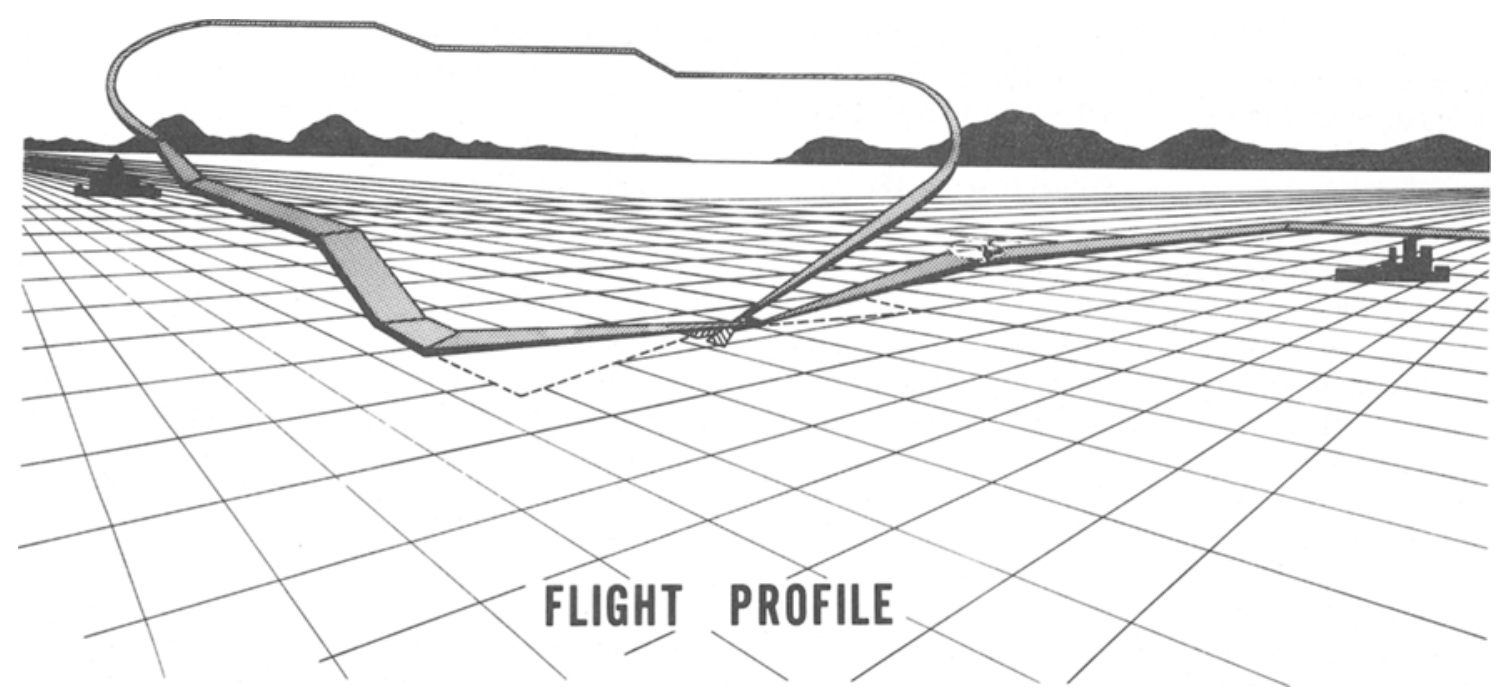

Figure 1. A 1-h flight profile.

dinates. After the last digit had been read aloud, the copilot was to quickly key the digits into a keyboard in the instrument panel. Time and error scores were recorded.

\section{Oculomotor Performance Measurement}

A modified National Aeromedical Corporation (NAC) Eye Mark recorder worn by the pilots and a Photosonic high-speed motion picture camera were used to record the subjects' oculomotor performance (Simmons, 1979) during portions of the 1-h flights. Measures of pilot visual scan patterns (frequency and dwell times) on crew station instruments were obtained.

\section{Pilot Subjective Ratings}

Immediately after each flight, the pilot was asked to rate how well he had performed at the controls, how fatigued he felt, and the degree of boredom he had experienced during the flight. The scales consisted of bipolar line drawings, and subjects placed a pencil mark along the line to indicate how they had felt or how well they thought they had performed.

\section{Oral Temperature}

Oral temperatures were taken by the pilots at approximately 4-h intervals throughout each test day and on the pre- and posttest rest days.

\section{Biochemical Measures}

Each morning, pilots provided urine specimens and breath effluent samples. This procedure was repeated at 2-h intervals between flights. Samples were also collected on pre- and posttest rest days. Urine specimens were analyzed for excretary rates of metabolites (urea, nitrogen, uric acid, triglycerides, creatinine, calcium, and phosphorus) and catecholamines (norepinephrine and epinephrine) as potential indicators of stress levels.
Breath effluent samples were collected in Bendix hydrocarbon absorbent tubes and were analyzed mass spectrometrically for the presence of isoprene, a metabolite of vitamin A, suspected to be a precursor to other biochemical and physiological indices of stress (Conkle, Camp, \& Welch, 1975; Larsson, 1965).

\section{Pilot Mood Scale}

Four times per day (upon awakening, prior to the noon and evening meals, and again before retiring), pilots completed a 67-item mood check list in a three-choice response format: placing a 1 for "not at all," a 2 for "somewhat or slightly," and a 3 for "mostly or generally." The mood questionnaire (Radloff \& Helmreich, 1968; Ryman, Biersner, \& LaRocco, 1974) gives a score on six scales: happiness, activity, depression, fear, anger, and fatigue.

\section{Pursuit Rotor Tracking and Visual Search Tasks}

Two laboratory tests were administered to obtain measures of pilot "reserve ability" during the week-long flying schedule. In the pursuit rotor tracking task, pilots used a photoelectric probe to track a light target over three geometric patterns: triangle, square, and circle. Time on target and error scores were collected. The pursuit rotor tracking task was performed three times per day: at noon, before the evening meal, and after midnight before the pilots retired. A detailed description of the pursuit rotor data collection, reduction, analyses, and results is contained in Stone, Krueger, and Holt (1982).

In the visual search task, subjects scanned an array of 144 Landolt $C$ rings arranged in a $12 \times 12$ matrix rearprojected onto a viewing screen. The gaps in the $\mathrm{C}$ rings were variously oriented in eight different positions: top, bottom, left, right, and at $45^{\circ}$ between any of these. The subject's task on any trial was to identify the matrix grid 
locations of Landolt rings whose gaps appeared in two different prescribed positions, for example, all those Cs with openings to the lower left and also those with openings at the top. Subjects controlled the amount of time the array was displayed by operating a switch with the same hand that they used to write their responses. Correct identification of the " $C$ " locations and the visual search time were the measures collected.

\section{Flight Surgeon Evaluations}

The medical monitor, a flight surgeon, examined the aviators each morning. Evening examinations were performed by two flight surgeons serving as subjects in a study of physicians' diagnoses of "fatigued aviators." Conversations between the flight surgeons and the aviators were recorded.

\section{Psychological Tests}

During the pretest training, subjects completed the Raven Progressive Matrices test (Raven, 1956), a nonverbal intelligence scale, and the Minnesota Multiphasic Personality Inventory (MMPI, 1943), a self-report personality trait measurement test. Immediately after the last daytime flight on the 5 th day, subjects completed the MMPI a second time.

\section{Schedule}

There were three training/baseline (pretest) days, a controlled rest day at the laboratory on a Sunday, and then a schedule of 5 successive flight days (Table 2). The flights terminated at $1830 \mathrm{~h}$ Friday. The pilots flew $14 \mathrm{~h}$ per day for 4 days and $10 \mathrm{~h}$ on Day 5. A 10-min hot refuel break between flights permitted subjects to complete scheduled data collection (i.e., urine samples, breath effluent, temperature, and rating scales) and to switch positions in the simulator (pilot-copilot). Subjects were allowed to sleep for $4 \mathrm{~h}$ each day.

After the completion of the 5th flight day, the subjects rested at the laboratory until they had been released by the flight surgeon. The pilots returned 2 days later to participate in a flight performance recovery (posttest) day of testing.

\section{Feedback}

During the sustained-schedule portion of the experiment, the pilots were permitted periodic glimpses of the graphic plots of their flight performance; these were viewed on the experimenters' consoles between flights.

\section{RESULTS AND DISCUSSION}

Preliminary analyses of the data are presented here. More reports on this experiment are forthcoming upon completion of subsequent data analyses.

\section{Flight Performance Overview}

Each of the six aviators completed the 66-h 5 day flight schedule with $4 \mathrm{~h}$ sleep per night. Pilots flew the simulator quite well most of the time. They flew assigned head- ings, airspeeds, altitudes, and turn rates (the psychomotor tracking portions of flying) with precision for hours, even days, at a time. For most flights, the subjects navigated correctly. However, pilots made occasional cognitive errors, such as flying off a well-practiced course, telling the air traffic controller they were at an intersection before they had reached it, and turning to intersect navigation bearing radial beacons too early or too late. Some of these errors were judgmental miscalculations in navigating. Others resulted from misreading instruments.

Level flight. We had hypothesized that pilot performance would change as a function of the number of days into the extensive flight operations. Each pilot's performance was analyzed on 4 flight days: the final training day (pretest), the 1st and 4th flight days in the test, and the recovery flight day (posttest). Two 4-min segments of level flight from each pilot's first flight on those 4 days were selected for the analysis. Variables of interest were root-mean-square (RMS) error and average absolute error (AAE) in the performance of holding the assigned airspeed ( $90 \mathrm{knots})$, altitude $(4,000 \mathrm{ft})$, and heading $\left(270^{\circ}\right.$ and $330^{\circ}$ ).

A three-factor (crews, days, and segments-headings) repeated-measures analysis of variance (Winer, 1971) was performed on the level-flight data, with repeated measures analyzed for each pilot for days and segments.

Days. In general, from the pretest to the 4th test day, pilots improved their performance in holding assigned headings (AAE of $3.2^{\circ}$ vs. $1.7^{\circ}$ ) and altitudes (AAE of 54 vs. $29 \mathrm{ft}$ ) in cruise/level flight (Duncan's multiple range $p<.05$ ); but performance across the test days remained constant.

The means give good indications that the pilots were flying assigned headings and altitudes to close tolerances even on the morning of the 4th day of the study (heading: $\mathrm{RMS}=2.2^{\circ}$ and $\mathrm{AAE}=1.7^{\circ}$; altitude: $\mathrm{RMS}=$ $34 \mathrm{ft}$ and AAE $=29 \mathrm{ft}$ ). Such performance, especially that of holding the altitude to such close tolerances, is quite acceptable for IFR standards.

Flight crews. The analysis of variance revealed statistically significant effects between flight crews for all three dependent measures: heading, airspeed, and altitude on both measures of variability (RMS and AAE). F tests for five of six of these differences between crews were significant $[\mathrm{Fs}(2,3)=10.45$ to $25.64, \mathrm{p}<.05]$. Duncan's multiple range tests (Harter, 1960) for differences between the means were performed on all significant effects.

The second crew of two pilots controlled the simulator with less precision than did the first and third crews. For example the second crew's AAE for heading was $2.8^{\circ}$, whereas it was only $1.2^{\circ}$ and $1.9^{\circ}$ for the other crews $(p<.01)$. The second crew's AAE for altitude was 48 $\mathrm{ft}$, whereas it was 40 and $24 \mathrm{ft}$ for the other two crews $(\mathrm{p}<.05)$.

Oculomotor performance analysis. Folds, Yunker, and Smith (1983) analyzed instrument takeoffs (ITOs), cross-country straight and level cruise flight segments, and instrument landing system (ILS) approaches to landing at airport runways during 1 -h flight profiles each day. 
Table 2

Daily Flying, Testing, and Sleeping Schedule

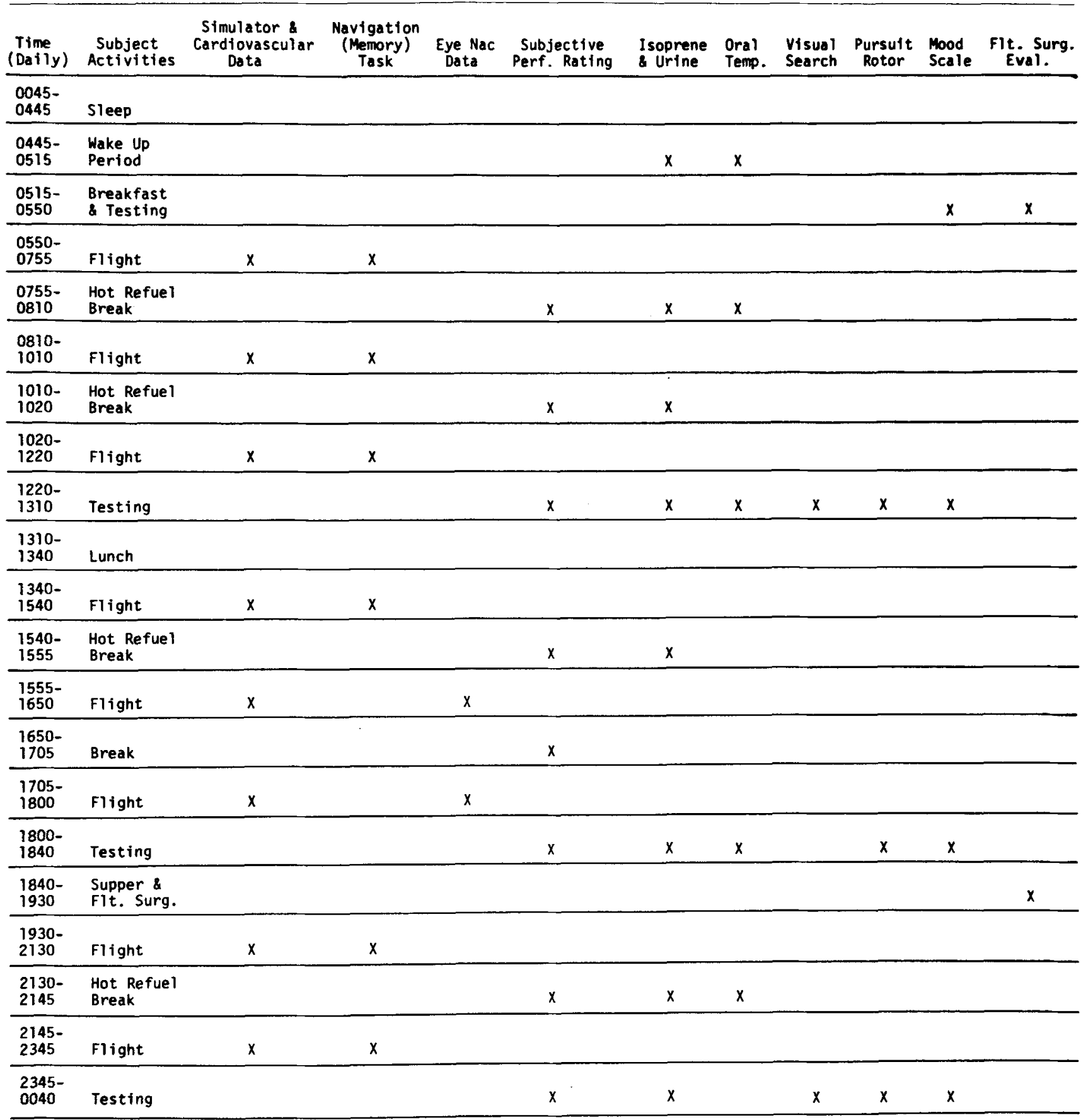

During instrument flight, pilots spent $60 \%$ of their visual time fixating on three instruments: the artificial horizon, radio magnetic indicator, and the omni-bearing selector. The pilots looked at four other instruments, the altimeter and the airspeed, vertical speed, and turn and bank indicators, about $18 \%$ of the time. These results closely approximate those found by Simmons, Lees, and Kimball
(1978). Analyses of scan rates (the frequency of looking at an instrument) and dwell times (time spent fixating an instrument) revealed differences as a function of the particular maneuver being performed, for example, an instrument takeoff versus an approach to landing. However, of more interest here is the fact that eye movement patterns did not change significantly across days. 
In the evaluation of pilot flight control performance, Folds et al. (1983) compared standard deviation of pilot control inputs on altitude, airspeed, heading, pitch, roll, and yaw for each of three maneuvers: ITO, cruise flight, and ILS landings. Again, no significant change in pilot control performance was detected as a function of days, thus further amplifying that the extensive flight week had not caused pilots to change their visual scan patterns and had not altered their flight control performance.

Autorotations. Occasionally, flights were interrupted by simulated engine failure emergencies. Pilots were required to "land" the simulator by performing an autorotation maneuver (in the absence of engine power, to control flight to the ground by manipulating the pitch of the main rotor blades) according to established emergency procedures. Subjects experienced engine failures on the last training day, at scheduled points on the 1st, 3rd, and 5th test days, at a few other times scattered throughout the week, and again on the recovery day. Each pilot performed approximately 8 to 10 autorotations during the experiment.

Each autorotation was analyzed in two phases (Armstrong, Krueger, Sapp, \& Jones, 1978). In Phase 1, the first $20 \mathrm{sec}$ after the occurrence of the engine failure, the pilot was to diagnose the emergency and set up the aircraft conditions to maintain positive control. In Phase 2, the pilot attempted to maintain flight parameters to within tolerances of prescribed airspeeds, headings, rotor speeds, and flight attitude. Graphic analyses indicate a trend of improved pilot performance in both phases for successive autorotations over days or trials.

\section{Copilot Boredom and Nap-Taking}

Each pilot was requested to fly for 1- and 2-h missions. Direct sharing of the flight control duties was discouraged. This allowed measurement of flight performance on any one pilot over long periods. It also left the copilot with only his navigational chores and the short-term memory task to perform twice during each 2-h flight. Since the experiment called for frequent repetitions of the mission profiles, the navigation details were easily committed to memory, and the copilots eventually became bored. This was borne out by subject comments during the week and by postexperiment interviews.

Copilots were not busy, and there were occasional instances of short nap-taking in the cockpit. At times, the experimenters were not sure whether or not a copilot was actually asleep or was merely resting quietly, perhaps with his eyes closed. A low-light-level, closed-circuit camera focused on the crew could not make fine determinations of nap-taking. Copilot "naps" were more evident in the later portions of the week-long schedule and more common during night flights.

\section{Flight Surgeon Evaluations}

Morning evaluations elicited pilot reports of insomnia, boredom, and complaints of muscle cramps, backaches, ${ }^{1}$ and headaches. In the evening evaluations, the flight sur- geons reported strain and redness in the pilots' eyes, slowness to respond to questions, and pilots' own degrading self-critique of physical and mental well-being as the week progressed.

Blood pressures, body weights, heterophoria measurements obtained with Armed Forces Vision Testing Apparatus, and the results of general physical examinations were all found not to be useful indicators of fatigue because they did not change noticeably during the experiment. Subjective information given by the pilots about their own perceptions of their readiness to continue flying and easily administered mental status tests proved to be useful determiners of fatigue. In the mental status examination, mood status checks and memory and computational tests (such as remembering blood pressures and subtracting serial sevens) seemed to be reasonably good indicators of fatigue. The flight surgeons reported that a game of "Simon says" to gauge attentiveness also appeared to be a reasonably good predictor of fatigue. As the experiment progressed, subjects became less able to correctly follow the instructions of the game.

In the independent opinion of the three flight surgeons, five of the six subject aviators reached a point of significant fatigue, "when they were no longer safe to fly," by the evening of the 3rd day of the extensive flight schedule. They reported that the sixth aviator probably became unsafe by the evening of the 4th day, although he reported that his flying was beginning to deteriorate on the evening of the 2nd day. Despite these opinions of the physicians, the pilots continued to fly 28 out of the 48 more hours remaining in the 5-day experiment, and the data indicate that the pilots all were flying well, even into the 5th day,

\section{Pursuit Rotor Tracking}

The analysis of pursuit rotor tracking data (Stone et al., $1982)$ revealed a significant difference $(p<.05)$ in performance over days on the more complex target pattern (the triangle). The number of times the subject moved the tracking stylus onto the target decreased over days during night testing, but it was not accompanied by a commensurate change in the total time on target. It suggested a nocturnal effect in which the subjects seemed to "settle down." They had the same total amount of time on target with fewer moves onto the target, but only on the triangle, and only at night. Much like the evidence we have reported with regard to piloting performance (which contains a large amount of tracking), simple tracking tasks seem to be more resistant to the effects of extended flight schedules than are more complex tasks.

\section{REFERENCES}

Armstrong, R. N., Krueger, G. P., Sapp, J. H., \& Jones, Y. F. (1978). Oculomotor performance of aviators during an autorotation maneuver in a helicopter simulator. In S. C. Knapp (Ed.), Operational helicopter aviation medicine (NATO/AGARD CP 255). London: Technical Editing and Reproduction, Ltd. 
Behar, I., Kimball, K. A., \& Anderson, D. B. (1976). Dynamic visual acuity in fatigued pilots (USAARL Report No. 76-24). Fort Rucker, AL: U.S. Army Aeromedical Research Laboratory.

CONKLe, J. P., CAMP, B. J., \& Welch, B. E. (1975). Trace composition of human respiratory gas. Archives of Environmental Health, 30 , 290-295.

FISHER, K. D., \& CARR, C. J. (1968). An interim report on factors that affect the performance of Army flight crew personnel (Tech. Rep. No. 68-1). Bethesda, MD: Office of Biomedical Studies, Life Sciences Research Office, Federation of American Societies for Experimental Biology.

Folds, D. J., Yunker, G. W., \& Smith, T. A. (1983). Oculomotor flight control performance of aviators during extended flight operations in a helicopter simulator (Final Contract Report, Contract DAMD 17-81-C-1174). Jacksonville, AL: Jacksonville State University.

HARTER, H. L. (1960). Critical values for Duncan's new multiple range test. Biometrics, 16, 671-685.

Kimball, K. A., \& ANDERSON, D. B. (1975). Aviator performance: Biochemical, physiological and psychological assessment of pilots during extended helicopter flight. In H. S. Fuchs, G. Perdriel, \& A. Gubernale (Eds.), The role of the clinical laboratory in aerospace medicine (NATO/AGARD CP 180). London: Technical Editing and Reproduction, Ltd.

KRUEGER, G. P., \& FAGG, J. N. (1981). Aeromedical factors in aviator fatigue, crew work/rest schedules and extended flight operations: An annotated bibliography (USAARL Report No. 81-1). Fort Rucker, AL: U.S. Army Aeromedical Research Laboratory.

Krueger, G. P., \& JoNES, Y. F. (1978). U.S. Army aviation fatiguerelated accidents: 1971-1977 (USAARL Report No. 79-1). Fort Rucker, AL: U.S. Army Aeromedical Research Laboratory.

LARSSON, B. T. (1965). Gas chromatography of organic volatiles in human breath and saliva. Acta Chemical Scandinavia, 19, 159-164.

Lees, M. A., Kimball, K. A., \& Stone, L. W. (1977). The assessment of rotary wing aviator precision performance during extended helicopter flights. In R. Auffret (Ed.), Studies of pilot workload (NATO/AGARD CP 217). London: Technical Editing and Reproduction, Ltd.

Lees, M. A., Simmons, R. R., Stone, L. W., \& Kimball, K. A. (1978). Changes in the rotary wing aviator's ability to perform an uncommon low altitude reward hover maneuver as a function of extended flight requirements and aviator fatigue. In S. C. Knapp (Ed.), Operational helicopter aviation medicine (NATO/AGARD CP 255). London: Technical Editing and Reproduction, Ltd.
Lees, M. A., Stone, L. W., Jones, H. D., Kimball, K. A., \& ANDERSON, D. B. (1979). The measurement of man-helicopter performance as a function of extended fli ht requirements and aviator fatigue (USAARL Report No. 79-12). Fort Rucker, AL: U.S. Army Aeromedical Research Laboratory.

Minnesota Multiphasic Personality Inventory (MMPI). (1943). Minneapolis, MN: University of Minnesota; New York: The Psychological Corporation of New York.

PERRY, I. C. (Ed.). (1974). Helicopter aircrew fatigue (NATO/AGARD AR No. 69). London: Technical Editing and Reproduction, Ltd.

Radloff, R., \& Helmreich, R. (1968). Groups under stress: Psychological research in Sealab II. New York: Appleton-Century-Crofts.

Raven, J. C. (1956). Progressive matrices. London: Lewis. (U.S. distributor: The Psychological Corporation, New York, NY)

Ryman, D. H., Biersner, R. J., \& LaRocco, J. M. (1974). Reliabilities and validities of the mood questionnaire. Psychological Reports, 35, 479-484.

Simmons, R. R. (1979). Methodological considerations of visual workloads of helicopter pilots. Human Factors, 21, 353-369.

Simmons, R. R., Lees, M., \& Kimball, K. A. (1978). Visual performance/workload of helicopter pilots during instrument flight (USAARL Report No. 78-6). Fort Rucker, AL: U.S. Army Aeromedical Research Laboratory.

Stone, L. W., Krueger, G. P., \& Holt, W. R. (1982). Pursuit rotor tracking performance in conjunction with extended flight operations in a helicopter simulator (USAARL Report No. 82-6). Fort Rucker, AL: U.S. Army Aeromedical Research Laboratory.

U.S. DEPARTMENT OF THE ARMY. (1980). Army aviation: General provisions and flight regulations (Army Regulation AR 95-1). Washington, DC: Author.

WINER, B. J. (1971). Statistical principles in experimental design (2nd ed., pp. 539-540). New York: McGraw-Hill.

\section{NOTE}

1. All subjects complained of severe back pains and muscle soreness by the end of the 3rd flying day. Air-inflated doughnut-shaped cushions, commonly used for patients with hemorrhoids, and bed pillows were used for back and spine support to supplement the support provided by the soft cushioned rubber seats in the simulator. Without these supports, the pilots would not have continued the experiment. Proper back support must be provided for sustained flight operations. 